\title{
Effect of Weight on Mosquito (Aedes aegypti L.) Feeding ${ }^{1}$
}

Although extensive information is available with regard to how mosquitoes feed under various conditions ${ }^{2}$, Jones and PrLITI ${ }^{3}$ recently reported that hungry females when glued to a pin-head and placed on a human arm would not take blood. The present note describes a new method for studying feeding behaviour in mosquitoes and shows that the act of restraint itself does not necessarily prevent feeding.

The Bangkok strain of Aedes aegypti (L.) was maintained at $80^{\circ} \mathrm{F}$ and $80 \pm 5 \%$ R.H. 3-day-old fasting females were lightly anaesthetized with nitrogen and small pieces of glass or metal of known weights were glued on to the dorsal surface of the thorax or abdomen, using either a rubber cement (Carter's) or Elmer's 'Glue-All'. After $1 \mathrm{~h}$ the females with known weights were placed in a small plastic cage which was inverted on a human arm for $15 \mathrm{~min}$, and the number of females taking blood within this period was noted..

When weights of 1 to $5 \mathrm{mg}$ were placed on the thorax, 8 out of 10 mosquitoes took blood in $15 \mathrm{~min}$, and 2 landed on the arm but never attempted to feed. When 6 to $10 \mathrm{mg}$ weights were placed on the thorax, 1 out of 12 females was able to take blood, whereas the others were unable to stand erect on their legs. Their legs were abnormally spread and the insects either fell to one side or were unable to lift the head into a feeding position. When 11 to $15 \mathrm{mg}$ weights were added to the thorax, the mosquitoes stumbled and fell on their sides when they attempted to walk, and none attempted to feed. When weights were placed on the anterior part of the abdomen, the response of the mosquitoes was strikingly different in that all 10 females with 1 to $5 \mathrm{mg}$ weights fed on blood, and 7 out of 10 females with 6 to $10 \mathrm{mg}$ weights fed normally. With 11 to $15 \mathrm{mg}$ of weights on abdomen, only 1 out of 5 females pierced deeply into the skin, but she did not take blood. In all cases where weighted females took blood, they did so to repletion - to stage 5 on the PILITT and JONES ${ }^{4}$ scale of engorgement.

When most mosquitoes take blood, it is normally dispatched to the midgut ${ }^{5}$. To determine if weighting the female would alter this distribution, we dissected 26 weighted females which had taken blood. In most cases, the blood was found only in the midgut, but in 2 mosquitoes (which had 6 to $10 \mathrm{mg}$ weights on the abdomen) blood was also found in the 2 dorsal diverticulae and in the crop.
It is evident from our work that an average female mosquito can pierce the human skin and take a normal amount of blood while bearing on the thorax an external weight which is twice her own weight. When weights are placed on her abdomen, she can feed with an external weight 3 to 5 times her own normal body weight. Possibly, the greater tolerance of weight on the abdomen is due to a shift in the fulcrum of the body. Heavier weights completely prevent orientation of the proboscis to a normal feeding angle and thus make piercing impossible

Since Jones and PILITT ${ }^{3}$ were unable to force-feed pinned mosquitoes, we decided to re-test whether restraint alone would inhibit feeding. With this in mind, we carefully glued one end of a long human hair to the thorax of a series of 20 mosquitoes and the other end into a glass capillary. When offered a human arm, all tethered females quickly landed, probed and pierced the skin and fed on blood to repletion, thus proving that restraint alone does not prevent normal feeding. The technique of glueing a mosquito to a hair allows one to leash the insect, and thus permits a whole variety of studies on its behaviour in general under truly controlled conditions.

Résumé. Les moustiques femelles Aedes aegypti L., alourdies par des poids placés sur leur thorax ou leur abdomen, peuvent encore se repaître normalement de sang humain. Sur le thorax, elles tolèrent 2 fois le poids de leur corps et 3 à 5 fois sur l'abdomen. Le fait d'être attachées ne restreint pas leur capacité d'absorber du sang. En expose le moyen de tenir des moustiques en laisse.

\section{J. C. Jones ${ }^{6}$ and B. V. MadHukaR}

Department of Entomology, University of Maryland, College Park (Maryland 20742, USA), 5 June 1974.

\footnotetext{
1 Supported by an N. I. H. Grant No. AI 08477.

2 S. R. Christophers, Aedes aegypti. The Yellow Fever Mosquito. (Cambridge University Press, Cambridge 1960), p. 739.

3 J. C. Jones and D. R. Piliti, Biol. Bull. 145, 127 (1973).

4 D. R. Pilitit and J. C. Jones, J. med. Ent. 9, 334 (1972).

${ }^{5}$ A. N. Clements, The Physiology of Mosquitoes (Pergamon Press, Oxford 1963), p. 393.

${ }^{6}$ Supported by N. I. H. Career Development Award No. GM-21529.
}

\section{Changes in the Concentrations of Elements in Liver After Partial Hepatectomy}

The regenerating liver after partial hepatectomy constitutes a convenient model system for the study of growth control. Such studies are facilitated by the fact that the liver has a uniform structure, is composed of relatively few cell types and undergoes regular, controlled regeneration. The following report is concerned with the changes which occur in the concentrations of elements after $2 / 3$ liver resection. Neutron activation analysis was used to detect the elements.

Materials and methods. The experimental animals used were Sprague-Dawley rats (200 g, Mus rattus, BrunnthalMünchen). Animals were maintained in macrolon cages in climatised rooms $\left(21^{\circ} \mathrm{C}\right)$ under normal conditions of light/darkness. Water and food (Altromin ${ }^{\circledR}$ standard diet) were available ad libitum. According to a standard procedure $^{1}$, partial hepatectomy was carried out by removing the middle and left lobes of the liver $(2 / 3$ resection).

For determination of elements, the livers, which were removed without using metal instruments, were freezedried and irradiated for $1 \mathrm{~h}\left(\varnothing=2 \times 10^{12} \mathrm{n} / \mathrm{cm}^{-2} / \mathrm{sec}^{-1}\right.$, Triga Mark I Reactor, DKFZ, Heidelberg). Na, K, and Mn could be directly determined by integration of the lines at 1360, 1520 and $845 \mathrm{keV}$ respectively. After a few hours, the samples were treated with $\mathrm{H}_{2} \mathrm{O}_{2} / \mathrm{H}_{2} \mathrm{SO}_{4}$, and the elements, $\mathrm{Na}, \mathrm{K}, \mathrm{P}$ and $\mathrm{Br}$ were removed using a

1 G. M. Higgins and R. M. Anderson, Arch. Path. 12, 186 (1931). 